\title{
Understanding barriers to access and utilization of cervical cancer screening services among women living with HIV in Kenya and Uganda
}

1. Katwesige Wycliff 2. Kathya Cordova-Pozo 3. Peter Hagono 4. Ebenezer Obi Daniel 5. Abul Kalam

1. Public Health Officer- Response to Public Health Emergencies-Uganda Red Cross Society, Kampala Uganda, email: katnagaish@yahoo.com Tel: +256782091220 ORCID ID: https://orcid.org/0000-0003-4783-2368.

2. Kathya Cordova-Pozo (KCP): Lecturer at Radboud University, Nijmegen, The Netherlands, email: k.cordovapozo@fm.ru.nl, ORCID ID: https://orcid.org/0000-0003-0890-8657

3. Peter Hagono (PH), Psychosocial counselor at HOYMAS, Nairobi, Kenya. Email: hagonopeter@gmail.com Tel: +254 725683140

4. Ebenezer Obi Daniel (EOB): Project Manager at CUAMM Rumbek Centre, Lakes State, South Sudan, email: d.obi@cuamm.org, dannypressy@yahoo.com

5. Abul Kalam (AK) Program and Research Analyst- Qualitative Helen Keller International, Bangladesh Country Office. Email: a.kalam724@gmail.com

\section{Keywords}

Cervical cancer screening, women with HIV/AIDs, Health Belief Model, Low-resource setting, Uganda and Kenya. 


\begin{abstract}
Background: Invasive cervical cancer (ICC) is one of the most preventable and curable forms of cancer. In East Africa, primarily Uganda and Kenya, where HIV/AIDs are common, it is usually diagnosed late, resulting in a public health hazard due to its poor prognosis. ICC is the second most common malignancy causing maternal death. This study explored factors that impede access and utilization of ICC screening services among women living with HIV in low resource settings in Uganda and Kenya.
\end{abstract}

Methods: A cross-sectional study design employing qualitative and quantitative techniques were conducted in six selected health facilities in Uganda and Kenya. A systematic cluster randomized sampling was used to select health facilities from which women living with HIV were invited to participate in the interviews, including focus group discussions, and triangulated this with in-depth interviews and literature. Data collection, coding, categorization, and statistical analysis of quantitative data were employed to rank correlation among the most critical factors that hinder access to ICC screening services.

Findings: Two hundred thirty-two (232) out of 310 women completed the intervieweradministered questionnaire making the response rate $75 \%$. The results uncovered a negative correlation between the perception of barriers to access the services. Two variables, the perceived risk for having ICC and the perceived severity, may impact the likelihood of undergoing ICC screening. There was a positive correlation between the perceived risk for ICC and the perceived severity. Statistical analysis shows that results are valid and reliable.

Conclusion: The study uncovered the health system barriers affecting ICC screening services at health facilities in Kenya and Uganda. It highlights the strengths and challenges while providing recommendations to promote health to include the most vulnerable women with HIV/AIDS living in socially deprived areas.

\title{
Introduction
}

Invasive cervical cancer (ICC) refers to uncontrolled squamous cells on the cervix (1). ICC is ranked as the fourth most common cancer in women globally. It accounts for approximately 570,000 new cases, with 311,000 deaths in 2018 , representing $6.6 \%$ of all female cancers (1). Nearly $90 \%$ of ICC's global mortality occurs in low- and middle resource countries, including Uganda and Kenya (2). During the same year, Uganda (54.8\%) and Kenya (33.8\%) were ranked among the first 20 countries with the highest rates of ICC globally as $7^{\text {th }}$ and $10^{\text {th, }}$ respectively (2). 
Recent studies indicate that HIV-positive women have a higher risk of coinfection with HPV types, HPV reactivation, and ICC (3). A study in Kenya uncovered that HIV could significantly increase the risk of cervical pre-cancer and cancer development and a $6 \%$ prevalence of cervical pre-cancer and cancer among HIV-positive women (4). Also, in Kenya and Uganda, ICC is a public health concern as it leads to morbidity and mortality among women, particularly those with HIV co-infection.

In 2019, Kenya and Uganda were among the two countries with the third-largest epidemic of HIV in the world, each with 1.5 million people living with HIV. Besides, there was a $5 \%$ of HIV prevalence among adults (ages 15-49), and among them, only $80 \%$ were receiving antiretroviral treatment (ART) among adults (1).

A recent study conducted in Kenya revealed that out of the 1180 women interviewed, $16.4 \%$ had been screened for ICC. For those unscreened women, $67.9 \%$ were already aware of ICC screening. The same study also revealed that high screening rates were observed in more educated women (5). However, the study did not explore more reasons for this and the need for more qualitative inquiry. Besides, the uptake of ICC screening services in Kenya is deficient at $3.2 \%$, below the target of $70 \%$, and hence, a dire need to study the factors that lead to low uptake of the screening services (6). In Uganda, Mitchell and colleagues' study indicated that $98.9 \%$ of women living with HIV did not think it was necessary to be screened for ICC despite being at higher risk than their HIV-negative counterparts (7). In 2013, the Uganda Ministry of Health planned to enhance targeted interventions to improve free access to essential health services, including ICC screening (8). In line with the above, a United States Agency for International Development (USAID) supported ICC screening programs in Kyenjojo District western Uganda through health workers' training. It provided cryotherapy equipment for two health facilities named Kyenjojo Hospital and Kyarusozi Health Center IV. However, the district's uptake of these services, especially for women with HIV, remained low (9). Other studies have also reported that three in four HIV-positive women remained under-screened for ICC (10). On top of this, various socio-political and cultural barriers may hinder effective HIV prevention programming in Kenya and Uganda, implying that new HIV infections are expected to rise in coming years, with annual new conditions projected to multiply around 340,500 in 2025 (11). Understanding the barriers to access and utilization of screening services is critical to addressing the above challenges amongst women with HIV. There is a lack of empirical research to explore the multi-faced barriers to uptake of ICC services amongst women with HIV in the hospital $(5,12)$. Hence, this study aims to assess the factors that hinder access and utilization of ICC screening services among women with HIV in Uganda and Kenya based on the health belief model (HBM) framework. 


\section{Materials and Methods}

Study design. A cross-sectional study design employing both quantitative and qualitative techniques was employed. A quantitative study involving the single population proportion formula was used to calculate the sample size. Sample size calculation was based on the proportion of participants who were aware of cervical cancer. The qualitative study was underpinned by ethnographic theory to understand and interpret intricate behavioural patterns (13). Inductive and deductive (pseudo-deductive) approaches were employed based on the health belief model (HBM) theoretical framework. HBM has six main components founded on perception: barriers, benefits, perceived risk (or susceptivity), severity, which leads to action (14). This conceptual model was chosen because it addresses the participant's inner world (values, beliefs, feelings, memories). HBM was also used to design the research questions, collect empirical data, and analysis $(14,15)$. The goal was to understand why not access and utilize the ICC screening services among women living with HIV in six selected health facilities of Kenya and Uganda.

This study involved three study participants: women living with HIV, key informants, and heath-service providers. A purposive, flexible, and emergent sample was used to identify participants for the focus group discussions (FGDs), the in-depth interviews (IDIs), and key informants $(\mathrm{KI})$ on the basis that they were likely to generate valuable data for the study (15). These three different data collection techniques capture diverse information and insights to complement each method until reaching convergence in the most critical aspects and triangulation while capturing the topic's multiple perspectives (using different moderators, locations to reach deep saturation, and comprehensiveness) (13). This could ensure the collected data's validity and reliability and its results $(13,16)$.

The sample included only women living with HIV aged between 19-49 years and attending sexual and reproductive health care with antiretroviral therapy (ART). They were recruited from six hospitals that provide these services in Uganda and Kenya. They were invited by trained research assistants and randomly assigned to FGDs. The characteristics and number of participants are detailed in the table below (

\section{Table 1).}


Table 1. Kenya and Uganda: Number and socio-economic characteristics of participants

\begin{tabular}{|c|c|c|c|c|c|c|c|c|c|}
\hline & & & & Kenya & & & & Uganda & \\
\hline Level of & & Primary & & Seconda & & Primary & & Secondary & \\
\hline & & 73 & & 47 & & 22 & & 15 & \\
\hline Distance & e to the hospital & $<10 \mathrm{Km}$ & & $>10 \mathrm{Km}$ & & $<10 \mathrm{Km}$ & & $>10 \mathrm{Km}$ & \\
\hline & & 68 & & 52 & & 30 & & 7 & \\
\hline & & $\begin{array}{l}\text { Number } \\
\text { ea. FGDs }\end{array}$ & $\begin{array}{c}\text { Number } \\
\text { ea. IDI }\end{array}$ & $\begin{array}{r}\text { Numbe } \\
\text { ea. KII }\end{array}$ & $\begin{array}{r}\text { Total number } \\
\text { of Participants }\end{array}$ & $\begin{array}{l}\text { Number } \\
\text { ea. FGDs }\end{array}$ & $\begin{array}{c}\text { Number } \\
\text { ea. IDI }\end{array}$ & $\begin{array}{c}\text { Number } \\
\text { ea. KII }\end{array}$ & $\begin{array}{r}\text { Total number } \\
\text { of Participants }\end{array}$ \\
\hline Women & HIV (WHIV) (8-10 participants) & 99 & 10 & --- & 109 & 24 & 13 & --- & 37 \\
\hline City & Name of the Hospital & & & & & & & & \\
\hline Nairobi & The Coptic Hospital & 14 & 3 & & 2 & & & & \\
\hline Kiambu & Kiambu Referral Hospital & 17 & 2 & & 2 & & & & \\
\hline & Ngong Hospital & 19 & 1 & & 2 & & & & \\
\hline Kajiado & Kitengela Hospital & 20 & 3 & & 2 & & & & \\
\hline & Isinya Hospital & 29 & 1 & & 3 & & & & \\
\hline Service $\mathrm{p}$ & & & & 11 & & --- & --- & 1 & 1 \\
\hline Hospital & and Administrators & -- & --- & --- & & --- & --- & 1 & 1 \\
\hline Partners & s cervical cancer screening programs & --- & --- & -- & & --- & --- & 1 & 1 \\
\hline Total par & & 99 & 10 & 11 & 120 & 24 & 13 & 3 & 40 \\
\hline Total nur & ejected to participate & 16 & 5 & 3 & 24 & 5 & 1 & 1 & 7 \\
\hline
\end{tabular}

In Uganda, the study was conducted in Kyenjojo Hospital, a public health facility in a deprived setting of Kyenjojo district, Western Uganda. It has a total population of 422,204 people, whereby $39.7 \%$ of the females above 18 years are illiterate (17). About $66 \%$ of the households are within five kilometers of proximity to the nearest public health facility (17). In Kenya, the study was conducted at five hospitals in three different counties of Kenya, Nairobi (3.2 million population), Kiambu (2.5 million), and Kajiado (1.18 million people) (17). The Coptic Hospital (Nairobi County) is a church-based health facility managed by the Orthodox church and is situated $4.5 \mathrm{~km}$ from the Nairobi Central Business District (CBD). The Kiambu hospital (Kiambu County) is located about $16 \mathrm{~km}$ from the Nairobi CBD. Kajiado County borders Nairobi to the South, with its headquarters about $80.5 \mathrm{~km}$ from Nairobi city center with three public hospitals for the study, namely, Ngong, Isinya, and Kitengela. Most residents in these two counties live in deprived-resource settings and are either peasant farmers or pastorals. In Uganda, $23 \%$ of the females aged above 18 years are illiterate (17). The data collection process lasted three weeks (Mid-January until February 2019) in Uganda and eight weeks (January until mid-March 2020) in Kenya. FGDs used structured guidelines based on the HBM model (risk perception of ICC, awareness of ICC screening programs, perceived severity, barriers that impede access to ICC, and motivators to ICC screening) 
with open-ended questions (divergence). The content used literature and study experts to validate to pilot test.

The Research Assistants (RA) trained for two days and piloted the data collection tools to collect later in the field using local language (Runyoro-rutooro in Uganda and Swahili in Kenya) FGDs informed consent was signed.

\section{Analysis and findings}

The information was transcribed verbatim by the principal and co-investigator, who also coded within the HBM themes. Qualitative data analysis involved; coding, memo writing, comparison, categorization of emerging data (18). No software was employed. A thematic analysis was applied by the aggregation method with scoring (per number of participants in each hospital's FGD) to synthesize information and explain the main perceived aspects in a rank-order per HBM component (19). The quantitative analysis involved logistic regression in creating odds ratios to determine the strength of association between independent and dependent variables using a significance level of $p<0.05$. This obtained the shares, the main descriptive statistics, and the $95 \%$ confidence interval $(\alpha=0.05)$. Statistical tests were applied to check for external validity and reliability (20) with a correlation test among the HBM components (19). A normality test to check if the sample size was large enough to reflect the population is a standard probability distribution in the natural world $(16,20)$. Incomplete questionnaires were excluded from all analyses.

\section{Ethics approval}

The study was reviewed and registered in Uganda by the Texila American University School of Public Health Ethics and Research Committee. The University of Nairobi School of Public health's ethics and research committee approved the study in Kenya.

\section{Results}

Thirty-eight (38) sub-themes for Kenya and 61 for Uganda were categorized within the HBM components (appendix 1). Table 2 displays describe $50 \%$ of the data with the most mentioned sub-themes in Kenya and Uganda. 
Table 2. HBM components with the top 50\% sub-themes mentioned.

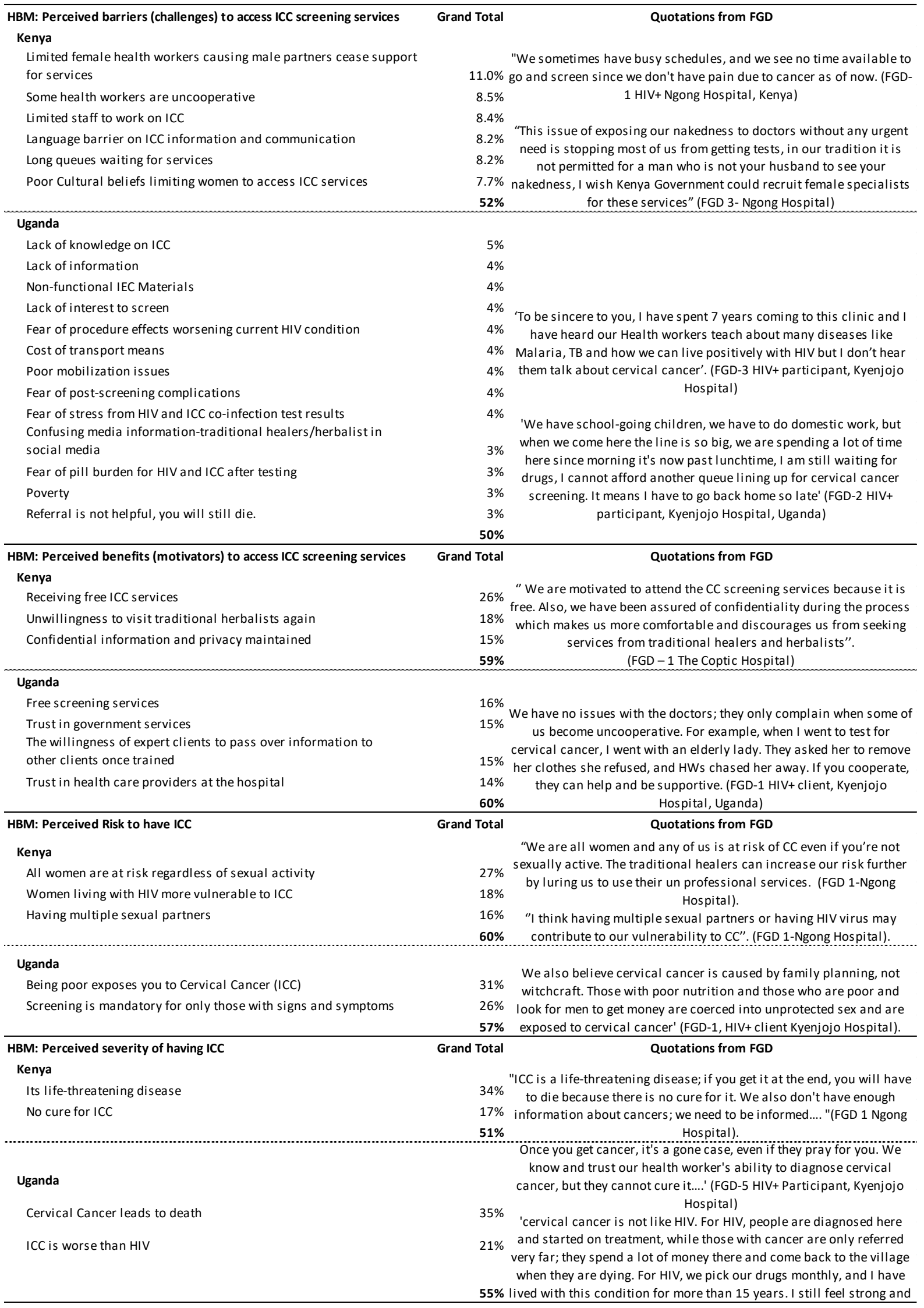




\section{Perceived access barriers}

Table 2 displays the reasons that women with HIV do not access ICC screening services. A common sense in both countries is that health workers with a lack of interest or poor cooperation hinder access to services. Other reasons are particular to each country among which is the unawareness of the ICC services, for the examination procedure (metallic instruments, the pain, and exposure), a lack of knowledge and information about ICC screening services, complications of referral (transport costs, accessing the services, time in the queue). Besides, confusing media information regarding traditional healers' capacity to cure every disease misleads towards cancer prevention.

\section{Perceived benefits}

Table 2 shows driver factors as motivators for the uptake of ICC screening services. Common drivers are based on free ICC screening services, trust in health services, and healthcare providers. Women that make regular visits to the facility for their HIV conditions may be offered to get the screening at no cost. Understanding the benefits of knowing their ICC status and the hope to access free treatment is crucial for screening. And the willingness of expert clients to be trained to provide health education on ICC (Uganda).

\section{Perceived risk}

Table 2 shows the main aspects that women living with HIV feel about the risk of (having) cervical cancer. There are no common factors among the $50 \%$ topics. Still, the ones mentioned in Kenya are that all women are at risk regardless of sexual activity, multiple sexual partners, or women with HIV who are vulnerable to ICC. In Uganda, most women with HIV believe that ICC testing was only mandatory for women who had symptoms or that poverty is a significant factor.

\section{Perceived severity}

Table 2 shows the main aspects that women living with HIV feel about cervical cancer severity (to their body). In both countries, women living with HIV coincide that cervical cancer leads to death and no cure.

\section{Validity, reliability, and generalizability}

In social science, robustness cannot be assumed because of small sample sizes. Hence, to test the results' robustness, a normality test is a necessary condition to obtain parameter estimates that are efficient and unbiased (20). Table 3 shows a skewness probability with a $p$-value of skewness $>0.05$ for all topics except for perceived severity implying that 
skewness is asymptotically normally distributed. Similarly, the Kurtosis probability indicates that it is also asymptotically distributed for all subjects ( $p$-value of kurtosis $>0.05)$. Finally, the joint probability chi-square of Skewness and Kurtosis is more significant than $0.05(\alpha=0.05)$ for all topics except for the perceived severity. Subsequently, the null hypothesis cannot be rejected, which means that residuals show a normal distribution for all components except for Kenya's perceived severity. Perceived risk and severity in Uganda could not be tested due to insufficient observations. These results provide an external validity or generalizability of the products for these two countries.

Table 3. Aggregation of mentioned items, descriptive statistics, and normality test

\begin{tabular}{|c|c|c|c|c|c|c|}
\hline Kenya & HBM Topic & $\begin{array}{l}\text { Perceived } \\
\text { barriers }\end{array}$ & $\begin{array}{l}\text { Perceived } \\
\text { benefits }\end{array}$ & $\begin{array}{l}\text { Perceived } \\
\text { Risk }\end{array}$ & $\begin{array}{l}\text { Perceived } \\
\text { severity }\end{array}$ & Grand Total \\
\hline \multirow{5}{*}{$\begin{array}{l}\text { \# of mentioned sub-themes per } \\
\text { HBM component, per person and } \\
\text { per hospital }\end{array}$} & Coptic Hospital & 17.62 & 7.15 & 9.08 & 7.00 & 40.85 \\
\hline & Isinya Hospital & 11.48 & 6.96 & 6.30 & 5.85 & 30.59 \\
\hline & Kiambu Hospital & 16.31 & 8.00 & 5.56 & 5.38 & 35.25 \\
\hline & Kitengela Hospital & 14.79 & 7.37 & 8.47 & 6.42 & 37.05 \\
\hline & Ngong Hospital & 16.06 & 6.17 & 6.44 & 6.22 & 34.89 \\
\hline \multirow{5}{*}{ HBM component, per person } & share in percentage & $42.7 \%$ & $20.0 \%$ & $20.1 \%$ & $17.3 \%$ & $100 \%$ \\
\hline & mean & 15.3 & 7.1 & 7.2 & 6.2 & 35.73 \\
\hline & Lower bound, $95 \% \mathrm{Cl}$ & 12.7 & 6.4 & 5.5 & 5.5 & \\
\hline & Upper bound, $95 \% \mathrm{Cl}$ & 17.8 & 7.9 & 8.9 & 6.9 & \\
\hline & SD & 2.1 & 0.6 & 1.4 & 0.5 & \\
\hline \multirow{3}{*}{$\begin{array}{l}\text { Normality test of sub-themes } \\
\text { within HBM }\end{array}$} & Pr(Skewness) & 0.05 & 0.09 & 0.86 & 0.01 & \\
\hline & $\operatorname{Pr}$ (Kurtosis) & 0.31 & 0.66 & 0.37 & 0.48 & \\
\hline & joint Prob>chi 2 & 0.090 & 0.179 & 0.643 & 0.046 & \\
\hline Uganda & HBM Topic & $\begin{array}{l}\text { Perceived } \\
\text { barriers }\end{array}$ & $\begin{array}{l}\text { Perceived } \\
\text { benefits }\end{array}$ & $\begin{array}{l}\text { Perceived } \\
\text { Risk }\end{array}$ & $\begin{array}{c}\text { Perceived } \\
\text { severity }\end{array}$ & Grand Total \\
\hline \multirow{2}{*}{ \# of sub-themes, per person } & share in percentage & $64 \%$ & $18 \%$ & $8 \%$ & $9 \%$ & $100 \%$ \\
\hline & mean & 128.83 & 36.83 & 16.79 & 17.38 & 199.83 \\
\hline \multirow{3}{*}{$\begin{array}{l}\text { Normality test of sub-themes } \\
\text { within HBM }\end{array}$} & $\operatorname{Pr}($ Skewness) & 0.979 & 0.640 & & few observations & \\
\hline & $\operatorname{Pr}$ (Kurtosis) & 0.309 & 0.480 & & few observations & \\
\hline & joint Prob>chi 2 & 0.581 & 0.686 & & few observations & \\
\hline
\end{tabular}

Figure 2 shows a chi-square test of independence to examine the relationship among the two countries' HBM components. The chi-square value is 534.476 with a p-value below 0.05 validates the alternative hypothesis, indicating a relationship between countries and the HBM components, rejecting the null hypothesis. This figure shows that the HBM components are comparable, even though each country has its particularities, as presented above (table 2). For both countries, perceived barriers have the highest share (42.8\% for Kenya and $64.5 \%$ for Uganda), followed by the perceived benefits or motivators (19.9\% for Kenya and $18.4 \%$ for Uganda). The illness's perceived risk and severity are lower than $20 \%$ in Kenya and even lower than $9 \%$ in Uganda. This means that the factors that affect the uptake of ICC screening services among women that live with HIV in Kyenjojo District, Western Uganda, 
and in the three counties of Kenya (Nairobi, Kiambu, or Kajiado) were mainly based on the health system's barriers rather than in the risk or severity.

Figure 1. Comparative HBM components per country

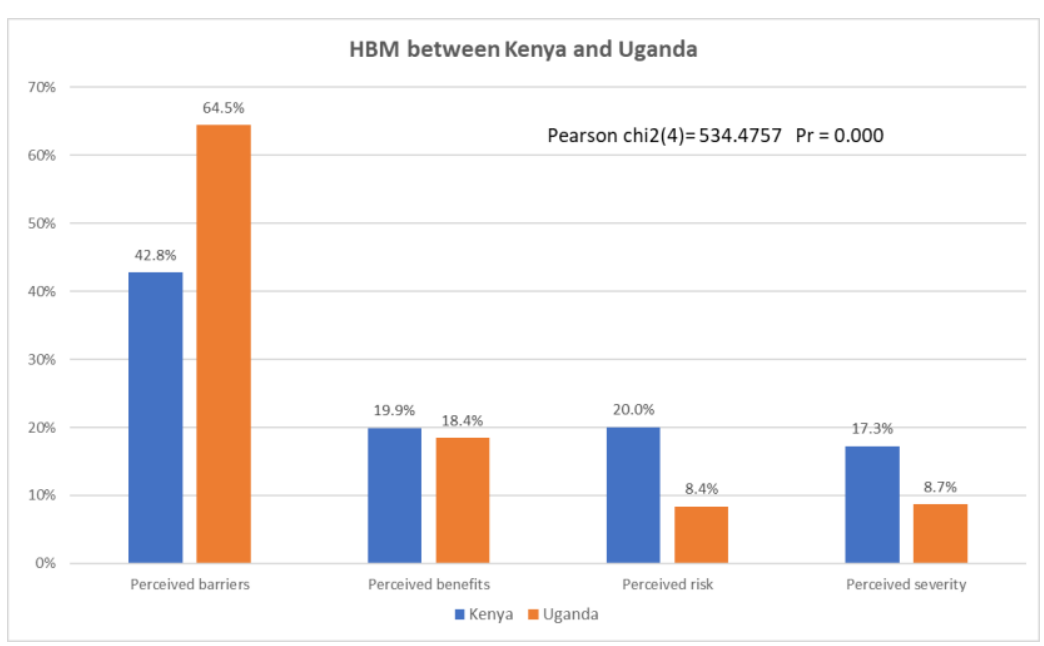

This analysis can uncover more detail running categorical correlations among both countries' HBM components (table 4). Table 4 displays a matrix of Pearson correlation which describes the direction and strength of the linear relationship between two HBM components under the assumption of normal distribution $(19,20)$. This shows the validity and reliability of results for the HBM framework. There is also a negative relation between the perceived barriers and the perceived risk (-0.9528, p-value 0.0033). This implies that if women with HIV have higher perceived barriers, their perceived risk for ICC is lower, which leads to a longer time to go to the hospital. Finally, there is a negative relation between the perceived barriers and the perceived severity $(-0.9482, \mathrm{p}$-value 0.004$)$. This means that if women with HIV have higher perceived barriers, the lower is their perceived severity for ICC, which leads to a longer time to go to the hospital. Finally, the perceived severity and perceived risks are positively correlated $(0.9, \mathrm{p}$-value 0.0143$)$, meaning that if women with HIV have a high perceived risk of ICC, this will also increase their perceived severity.

Table 4. Correlation between HBM components, Kenya and Uganda

\begin{tabular}{ccccc}
\hline & $\begin{array}{c}\text { Perceived } \\
\text { benefits }\end{array}$ & $\begin{array}{c}\text { Perceived } \\
\text { risk }\end{array}$ & $\begin{array}{c}\text { Perceived } \\
\text { severity }\end{array}$ & $\begin{array}{c}\text { Perceived } \\
\text { barriers }\end{array}$ \\
\hline Perceived benefits & 1 & & & \\
Perceived risk & 0.2207 & 1 & & \\
p-value & 0.6743 & & & \\
Perceived severity & 0.3174 & $\mathbf{0 . 9 0 0 7}$ & 1 & \\
p-value & 0.5398 & $\mathbf{0 . 0 1 4 3}$ & & \\
Perceived barriers & -0.4739 & $-\mathbf{0 . 9 5 2 8}$ & $\mathbf{- 0 . 9 4 8 2}$ & \\
p-value & 0.3424 & $\mathbf{0 . 0 0 3 3}$ & $\mathbf{0 . 0 0 4}$ & \\
\hline
\end{tabular}




\section{Discussion}

The uniqueness of this research is its focus on a vulnerable population, women living with HIV. They might have a higher risk of ICC due to their immunocompromised body system but do not access or use the ICC screening services. The study was carried among the countries with the highest rate of cervical cancer, Kenya and Uganda. The findings uncover a negative relation between the perception of barriers to access the services, two variables, the perceived risk for having ICC, and the perceived severity. Consequently, this impacts the likelihood of undergoing ICC screening. There is a positive relationship between the perceived risk for ICC and the perceived severity. Statistical analysis shows that results are valid and reliable. This is in line with the study of Mitchell, indicating that $98.9 \%$ of women with HIV did not think it was necessary to be screened for ICC despite being at higher risk than their HIV-negative counterparts (Mitchell et al., 2017). More, the uptake of ICCscreening in Kenya is at 3.2\%, below the targeted $70 \%$ (Munoru et al., 2019)

\section{Perceived Barriers and the negative correlation with perceived risk and perceived severity}

Despite both governments' efforts to train staff and provide ICC screening infrastructure and services to vulnerable persons, there were barriers to access services $(64.5 \%$ and $42.8 \%$ in Uganda and Kenya, respectively). The hindrances described included problems with the health personnel and long queues in Kenya and lack of knowledge, interest, or fear to access the ICC services. These findings are to a certain extend related to women with HIV conducted in urban settings in Uganda (21) (22), Kenya (23), and Nigeria (24), which could positively influence the validity of this research. Other studies mention that ICC screening's knowledge and awareness do not translate into increased service uptake (25). However, these studies focused on specific aspects while our research is rank-ordered and correlated the most critical components to present cues to action.

Our study indicates that the higher the perceived barriers, the less perceived risk. Phrases like "...visiting health facilities is common only when one has developed pain or symptoms of the disease...". Before this happens, the patient has a lower level of perceived risk or severity for ICC. Some studies focus on the need for culture-specific, sensitive information and interventions to improve the ICC screening uptake among women with fear (26) $(21,26,27)$. Other studies just focused on monetary barriers like Zimbabwe, as many could not afford ICC screening because of its costs (26).

In theory, women who knew the underlying risks or perceived severity would get ICC screening to know their status. However, when the barriers are too high, they tend to ignore these perceptions. In Uganda survey revealed that Cervical Screening uptake was deficient among HIV-infected women (9). Also, poor treatment outcomes and death and inaccessible 
referral facilities that manage ICC were mentioned barriers in Uganda (12) and Kenya (28). This may show that the higher the barriers, the lower their perception of risk or severity until the first symptoms appear.

The study reveals a positive correlation between the perceived risk to ICC with the perceived severity. Unfortunately, we did not find any study that could sustain this specific aspect more than the relationship with the barriers presented above.

\section{Limitations}

One of the limitations is that although many FGDs were organized in Uganda, this was done only in one hospital. The inclusion of more facilities could enhance the perspective. Furthermore, the HBM components were assessed as one. A split of perceived barriers or benefits in the availability, accessibility, acceptability, contact-use, and effectiveness, could bring more insights (29).

\section{Conclusions}

This study uncovered a myriad of sub-themes for ICC screening services at six selected health facilities in Uganda and Kenya. These factors were analyzed within the HBM framework and unveiled the relations between the perceived barriers and the length for accessing and utilizing the ICC services. And the positive relationship between the perceived risk and severity of the ICC. This could imply future actions to strengthen the health systems focusing on these factors and their main elements elicited within the HBM framework, particularly for vulnerable groups like women with HIV or deprived settings, which can positively contribute to the Sustainable Development attainment Goals.

\section{Consent for publication}

All authors and participants gave their consent for publication.

\section{Availability of data and material}

The datasets used and analyzed during the current study are available from the corresponding author on reasonable request. 


\section{References}

1. Rahman R, Clark MD, Collins Z, Traore F, Dioukhane EM, Thiam H, et al. Cervical cancer screening decentralized policy adaptation : an African rural-contextspecific systematic literature review Cervical cancer screening decentralized policy adaptation : an African rural-context-specific systematic literature review. Glob Health Action. 2019;12(1).

2. Davis V, Njama-meya D, Lim J, Murray M, Sanjose S De. Opportunities and challenges for introducing HPV testing for cervical cancer screening in sub-Saharan Africa. Prev Med (Baltim). 2018;114(July):205-8.

3. Lin LL, Lakomy DS, Chiao EY, Strother RM, Wirth M, Cesarman E, et al. Clinical Trials for Treatment and Prevention of HIV-Associated Malignancies in SubSaharan Africa: Building Capacity and Overcoming Barriers. J Glob Oncol [Internet]. 2020 Nov 22 [cited 2021 Mar 4];(6):1134-46. Available from: https://ascopubs.org/doi/10.1200/GO.20.00153

4. Ononogbu U, Almujtaba M, Modibbo F, Lawal I, Offiong R, Olaniyan O, et al. Cervical cancer risk factors among HIV-infected Nigerian women. BMC Public Health. 2013;13(1):1.

5. Nyangasi M, Nkonge NG, Gathitu E, Kibachio J, Gichangi P, Wamai RG, et al. Predictors of cervical cancer screening among Kenyan women: results of a nested case-control study in a nationally representative survey. BMC Public Health. 2018;18(3):1221.

6. Munoru F, Gitonga L, Muraya M. Integration of Cervical Cancer Screening Services in the Routine Examinations Offered in the Kenyan Health Facilities: A Systematic Review. Open J Obstet Gynecol. 2019;09(05):656-68.

7. Mitchell SM, Pedersen HN, Stime EE, Sekikubo M, Moses E, Mwesigwa D, et al. Self-collection-based HPV testing for cervical cancer screening among women living with HIV in Uganda : a descriptive analysis of knowledge, intentions to screen and factors associated with HPV positivity. BMC Women's Health. 2017;1-10.

8. Services H, Private W, Support S. Strides legacy series. 2015;(July 2009).

9. Wanyenze RK, Baptist J, Beyeza-kashesya J, Mugerwa S, Arinaitwe J. Uptake and correlates of cervical cancer screening among HIV-infected women attending HIV care in Uganda. Glob Health Action. 2017;10(1).

10. Craig P, Gibson M, Campbell M, Popham F, Katikireddi SV. Making the most of natural experiments: What can studies of the withdrawal of public health interventions offer? Prev Med (Baltim). 2018;108(October 2017):17-22.

11. Vithalani J, Herreros-Villanueva M, Vithalani J. HIV Epidemiology in Uganda: a survey based on age, gender, number of sexual partners, and frequency of testing. 2018;18(3):523-30.

12. Mukama T, Ndejjo R, Musabyimana A, Halage AA, Musoke D. Women's knowledge and attitudes towards cervical cancer prevention: A cross-sectional study in Eastern Uganda. BMC Women's Health. 2017;17(1):1-8. 
13. Vogl S, Schmidt EM, Zartler U. Triangulating perspectives: ontology and epistemology in analyzing qualitative multiple perspective interviews. Int J Soc Res Methodol [Internet]. 2019 Nov 2 [cited 2020 Oct 20];22(6):611-24. Available from: https://www.tandfonline.com/doi/full/10.1080/13645579.2019.1630901 14. Abraham C, Sheeran P. The health belief model. In: Cambridge Handbook of Psychology, Health, and Medicine, Second Edition. 2014. p. 97-102.

15. Bricki N, Green J. A Guide to Using Qualitative Research Methodology. Med Sans Front. 2007;11-3.

16. Leung L. Validity, reliability, and generalizability in qualitative research. J Fam Med Prim Care [Internet]. 2015 [cited 2020 Oct 20];4(3):324. Available from: /pmc/articles/PMC4535087/?report=abstract

17. KNBS. Population by Sex and Age Groups - KNBS Open Data Portal [Internet]. Kenya National Bureau of Statistics. 2020 [cited 2020 Oct 18]. Available from: http://knbs.or.ke/visualizations/?page_id=3126

18. Holton J, Khalsa-zemel S. From the Editor's Desk. 2018;17(1):1-107.

19. Odom LR, Morrow JR. What's this r? A correlational approach to explaining validity, reliability, and objectivity coefficients [Internet]. Vol. 10, Measurement in Physical Education and Exercise Science. 2006 [cited 2021 Mar 2]. p. 137-45. Available from:

https://www.tandfonline.com/action/journallnformation?journalCode $=$ hmpe20

20. Kim H-Y. Statistical notes for clinical researchers: assessing normal distribution (2) using skewness and kurtosis. Restor Dent Endod [Internet]. 2013 [cited 2021 Jan 31];38(1):52. Available from: https://www.ncbi.nlm.nih.gov/pmc/articles/PMC3591587/

21. Bukirwa A, Mutyoba JN, Mukasa BN, Karamagi Y, Odiit M, Kawuma E, et al. Motivations and barriers to cervical cancer screening among HIV-infected women in HIV care: A qualitative study. BMC Women's Health. 2015;15(1):1-11.

22. Ndejjo R, Mukama T, Musabyimana A, Musoke D. Uptake of cervical cancer screening and associated factors among women in rural Uganda: A cross-sectional study. PLoS One. 2016;11(2):1-13.

23. Rosser JI, Njoroge B, Huchko MJ. Knowledge about cervical cancer screening and perception of risk among women attending outpatient clinics in rural Kenya. Int J Gynecol Obstet. 2015;128(3):211-5.

24. Modibbo FI, Dareng E, Bamisaye P, Jedy-Agba E, Adewole A, Oyeneyin L, et al. Qualitative study of barriers to cervical cancer screening among Nigerian women. BMJ Open. 2016;6(1).

25. Hasahya OT, Berggren V, Sematimba D, Nabirye RC, Kumakech E. Olivia, et al., 2016: A qualitative study among women in Uganda following completion of an HPV vaccination campaign. Glob Health Action. 2016;9(1):1-9.

26. Ndejjo R, Mukama T, Kiguli J, Musoke D. Knowledge, facilitators and barriers to cervical cancer screening among women in Uganda: A qualitative study. BMJ Open. 2017;7(6):1-8. 
Afric

ArXiv

27. Hasahya OT, Berggren V, Sematimba D, Nabirye RC,

Kumakech E. Beliefs, perceptions and health-seeking behaviors in relation to cervical cancer : a qualitative study among women in Uganda following completion of an HPV vaccination campaign. 2016;1:1-9.

28. Oketch SY, Kwena Z, Choi Y, Adewumi K, Moghadassi M, Bukusi EA, et al. Perspectives of women participating in a cervical cancer screening campaign with community-based HPV self-sampling in rural western Kenya: A qualitative study. BMC Women's Health. 2019;19(1):1-10.

29. WHO Regional Office for Africa. Assessment of barriers to accessing health services for disadvantaged adolescents in Nigeria. 2019. 